\title{
Policies and Guidelines on Research Ethics and Conflict of Interest in Domestic Journals of Complementary and Alternative Medicine: An Example in Japan
}

\author{
Shoko Masuyama ${ }^{1,2}$ and Hitoshi Yamashita ${ }^{1,2 *}$ \\ ${ }^{1}$ Graduate School of Health Sciences, Morinomiya University of Medical Sciences, Japan \\ ${ }^{2}$ Morinomiya University of Medical Sciences Acupuncture Information Center, Japan
}

Submission: November 23, 2017; Published: November 28, 2017

*Corresponding author: Hitoshi Yamashita, LAc, PhD, Professor, Graduate School of Health Sciences, Morinomiya University of Medical Sciences,

1-26-16 Nanko-Kita, Suminoe-Ku, Osaka, 559-8611, Japan, Email: yamashita@morinomiya-u.ac.jp

\section{Opinion}

In the early 2010s, research misconduct became a major issue in Japan following some scandals both in the fields of basic and clinical research [1,2]. Accordingly, Ministry of Health, Labour and Welfare, Science Council of Japan and Japan Medical Association revised their guidelines to manage conflict of interest
(COI) more rigorously and ensure research integrity. Also, many academic societies revised their bylaws, policies and guidelines in terms of COI management. Although this movement may have influenced the policy and guidelines in complementary and alternative medicine (CAM) journals in Japan, the present status had not been reviewed.

Table 1: Description related to COI and other research ethics issues in "instructions to authors" in domestic acupuncture/CAM journals in Japan.

\begin{tabular}{|c|c|c|c|c|c|}
\hline Journal Title & $\begin{array}{l}\text { COI Disclosure } \\
\text { Form }\end{array}$ & $\begin{array}{l}\text { COI Statement in } \\
\text { Manuscript }\end{array}$ & $\begin{array}{l}\text { Clinical Trial } \\
\text { Registration }\end{array}$ & $\begin{array}{c}\text { Ethics Committee } \\
\text { Approval }\end{array}$ & $\begin{array}{c}\text { Informed } \\
\text { Consent }\end{array}$ \\
\hline $\begin{array}{l}\text { Journal of the Japan Society of Acupuncture and } \\
\text { Moxibustion }\end{array}$ & No & Yes & Yes & Yes & Yes \\
\hline The Japanese Journal of Ryodouraku Medicine & No & No & No & No & No \\
\hline $\begin{array}{l}\text { Journal of The Japan Society of Modern Acupuncture } \\
\text { and Moxibustion Research }\end{array}$ & No & No & No & Yes & Yes \\
\hline $\begin{array}{c}\text { The Journal of the Japanese Traditional Acupuncture } \\
\text { and Moxibustion }\end{array}$ & No & Yes & No & No & Yes \\
\hline $\begin{array}{c}\text { The Journal of Japan College Association of Oriental } \\
\text { Medicine }\end{array}$ & No & No & No & No & No \\
\hline $\begin{array}{l}\text { Journal of the Japan Association of Shiraku } \\
\text { Acupuncture }\end{array}$ & No & No & No & No & No \\
\hline Kampo Medicine & Yes & Yes & Yes & Yes & Yes \\
\hline $\begin{array}{l}\text { The Journal of the Japanese Society of Balneology, } \\
\text { Climatology and Physical Medicine }\end{array}$ & Yes & Yes & Yes & Yes & Yes \\
\hline $\begin{array}{c}\text { Japanese Journal of Complementary and Alternative } \\
\text { Medicine }\end{array}$ & No & Yes & Yes & Yes & Yes \\
\hline Eastern Medicine & No & No & No & Yes & Yes \\
\hline Oriental Medicine and the Pain Clinic & No & No & No & Yes & Yes \\
\hline Japanese Journal of Integrative Medicine & No & Yes & No & No & Yes \\
\hline
\end{tabular}


In order to know the present conditions of recognition and policy regarding research ethics and COI on clinical research in academic societies of acupuncture and CAM in Japan, we collected "instructions to authors" in journals of acupuncture and CAM. We assessed if there are any description or rule in them on the following items: (1) COI disclosure form, (2) COI statement in manuscript, (3) clinical trial registration, (4) ethics committee approval, and (5) informed consent. As of the end of November 2016, we could collect the relevant documents of 12 acupuncture or CAM-related academic society journals. There were statements on (1) in 2 journals (16.7\%), (2) in $6(50.0 \%)$, (3) in 4 (33.3\%), (4) in 7 (58.3\%) and (5) in 9 (75.0\%). Only 2 society journals included all of the above 5 items. The details are shown in Table 1.

If an author read recommendations by International Committee of Medical Journal Editors (ICMJE) [3], s/he will understand all $\mathrm{s} /$ he has to do before submitting a manuscript. As far as we know in Japan, however, most authors in the field of CAM practice have never read the ICMJE recommendations, and we suspect some of them even do not know ICMJE. The most efficient way to make the authors aware of them is to refer to the recommendations or include extracts from them in "instructions to authors" in journals to which an author is going to submit a manuscript. The ICMJE recommendations are translated at least into nine languages other than English [4].

However, based on our survey results above, many of the domestic journals of acupuncture or CAM in Japan do not seem to fully recognize the importance of disclosure of COI and other research ethics issues stated in the ICMJE recommendations. We do not believe that Japan is an exception. As our opinion is based on the premise that international journals have already done with this issue, domestic CAM journals in every country should check if there are any room for improvement of their policies and guidelines regarding research ethics. This is because, for some CAM practitioners who intend to submit their manuscript for the first time, "instructions to authors" might be the first textbook to learn ICMJE recommendations, COI disclosure, clinical trial registration, and so on. We strongly feel the importance of this issue when we conduct a systematic review and meta-analysis including clinical trials published in domestic CAM journals. We believe this elementary and careful process will increase research integrity and eventually enhance credibility of CAM research for the sake of patients.

\section{Acknowledgement}

This work was supported by JSPS KAKENHI Grant Number 26460616. MS and HY are licensed acupuncturist in Japan and earn income from studying and teaching acupuncture.

\section{Conflict of Interest}

There is no other conflict of interest.

\section{References}

1. The Lancet editors (2013) Retraction - Valsartan in a Japanese population with hypertension and other cardiovascular disease (Jikei Heart Study): a randomized, open-label blinded end point morbiditymortality study. Lancet 382(9895): 843.

2. Editorial (2014) STAP retracted. Nature 511(7507): 5-6.

3. ICMJE (2016) Recommendations for the Conduct, Reporting, Editing, and Publication of Scholarly Work in Medical Journals Updated December 2016.

4. ICMJE (Accessed November 2017) Translations. ICMJE Web site. 